\title{
Stent-Assisted Coiling of Bifurcation Aneurysms May Improve Endovascular Treatment: A Critical Evaluation in an Experimental Model
}

\author{
J. Raymond, T.E. Darsaut, F. Bing, A. Makoyeva, M. Kotowski, G. Gevry, and I. Salazkin
}

\begin{abstract}
BACKGROUND AND PURPOSE: Endovascular treatment of wide-neck bifurcation aneurysms often results in incomplete occlusion or aneurysm recurrence. The goals of this study were to compare results of coil embolization with or without the assistance of selfexpandable stents and to examine how stents may influence neointima formation.
\end{abstract}

MATERIALS AND METHODS: Wide-neck bifurcation aneurysms were constructed in 24 animals and, after 4-6 weeks, were randomly allocated to 1 of 5 groups: 1) coil embolization using the assistance of 1 braided stent $(n=5)$; 2) coil embolization using the assistance of 2 braided stents in a Y configuration ( $n=5)$; 3) coil embolization without stent assistance $(n=6)$; 4) Y-stenting alone ( $n=4)$; and 5) untreated controls $(n=4)$. Angiographic results were compared at baseline and at 12 weeks, by using an ordinal scale. Neointima formation at the neck at 12 weeks was compared among groups by using a semiquantitative grading scale. Bench studies were performed to assess stent porosities.

RESULTS: Initial angiographic results were improved with single stent-assisted coiling compared with simple coiling $(P=.013)$. Angiographic results at 12 weeks were improved with any stent assistance $(P=.014)$. Neointimal closure of the aneurysm neck was similar with or without stent assistance $(P=.908)$, with neointima covering coil loops but rarely stent struts. Y-stent placement alone had no therapeutic effect. Bench studies showed that porosities can be decreased with stent compaction, but a relatively stable porous transition zone was a limiting factor.

CONCLUSIONS: Stent-assisted coiling may improve results of embolization by allowing more complete initial coiling, but these highporosity stents did not provide a scaffold for more complete neointimal closure of aneurysms.

$\mathbf{S}$ tents are increasingly used to assist coil embolization of intracranial aneurysms. Indications have shifted from treating those few aneurysms qualified as "otherwise untreatable"1-5 to recently being used to "improve or stabilize anatomical results." ${ }^{6,7}$ Important questions, such as whether stents do improve initial angiographic results or decrease recurrences compared with simple coiling, remain unanswered. ${ }^{8,9}$ Various increasingly

Received January 26, 2012; accepted after revision May 16.

From the Department of Radiology (J.R., T.E.D., A.M., G.G., I.S.), Centre Hospitalier de l'Université de Montréal, Notre-Dame Hospital, Montreal, Quebec, Canada; Division of Neurosurgery, Department of Surgery (T.E.D.), Mackenzie Health Sciences Centre, University of Alberta Hospital, Edmonton, Alberta, Canada; Service de Radiologie A (F.B.), Centre Hospitalier Universitaire Strasbourg, Université Strasbourg 1, Hôpital Civil, Strasbourg, France; and Department of Neurosurgery (M.K.), Centre Hospitalier Universitaire Vaudois, Lausanne, Switzerland.

Please address correspondence to Jean Raymond, MD, CHUM-Notre-Dame Hospital, Interventional Neuroradiology (NRI), 1560 Sherbrooke East, Pavilion Simard, Room Z12909, Montreal, Quebec, Canada H2L 4M1; e-mail: jean.raymond@umontreal.ca

Evidence-Based Medicine Level 2.

http://dx.doi.org/10.3174/ajnr.A3231 sophisticated techniques, such as $\mathrm{Y}$ and $\mathrm{X}$ stenting, have now been described for bifurcation aneurysms. ${ }^{10-12}$ Authors have generally been enthusiastic about clinical results. ${ }^{4,6,11}$ However, an appropriate preclinical evaluation of stent-assisted coiling of bifurcation aneurysms has never been performed. A liberal clinical use of stenting, aiming to improve anatomic results of coiling, should be preceded by some evidence that stenting does provide some benefits. Frequent claims are that stents have a potential to "reduce intra-aneurysmal flow," to "provide flow diversion," "-11 and to facilitate "endothelialization" or "intimal overgrowth" at the neck. $^{9}$

Here we report the in vivo results of stent-assisted coiling in a bifurcation model with a demonstrated propensity for recurrence. ${ }^{13}$ The following questions were addressed: Are immediate angiographic results more complete with stent-assisted coiling? Are follow-up angiographic results improved at 3 months? Although stent placement alone, without coiling, may not offer a realistic treatment alternative for most clinical bifurcation aneurysms, the experimental setting will be an occasion to observe the effects of Y-stenting alone in the same model. 

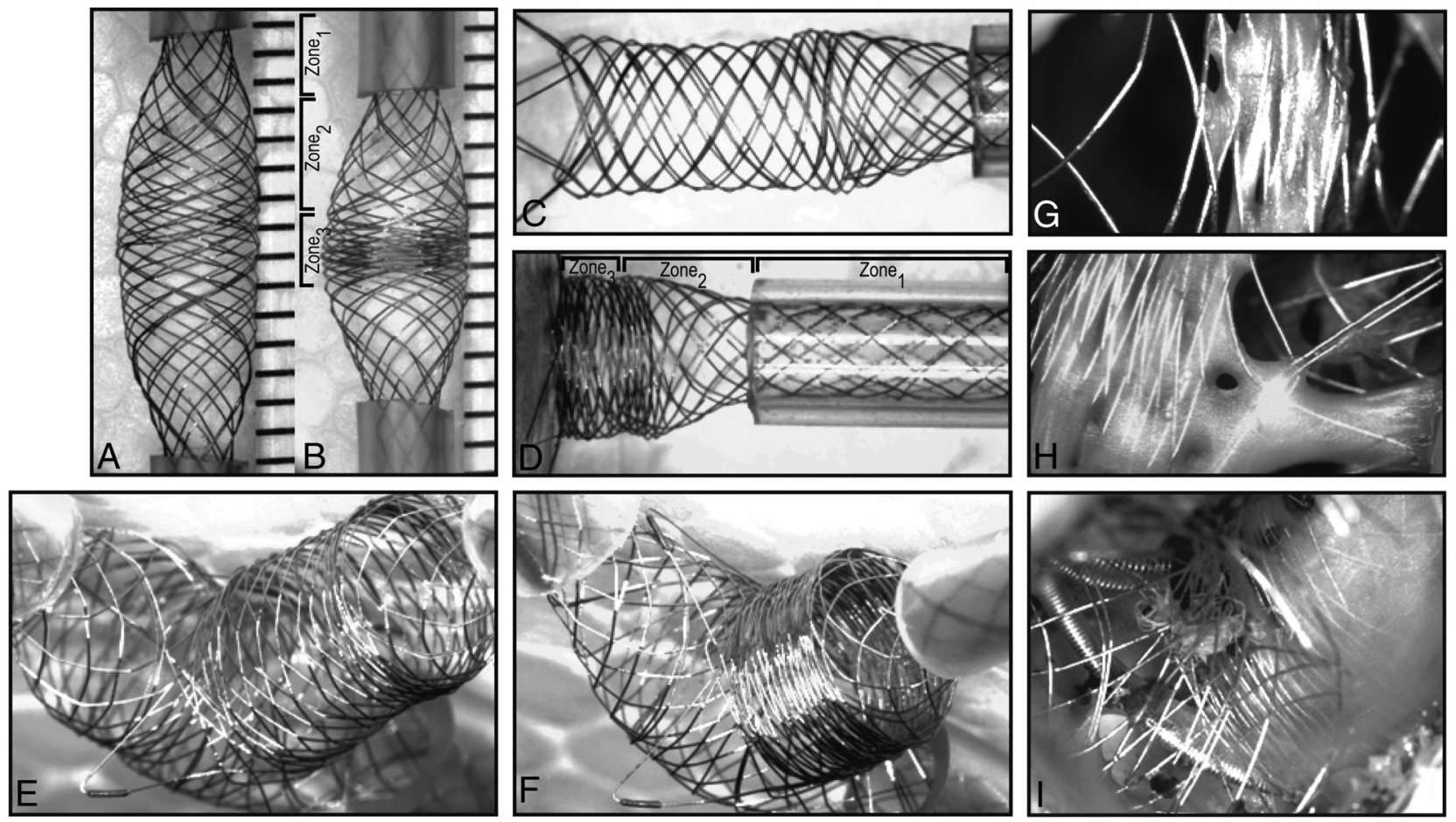

FIG 1. Bench studies. The experimental setup testing stent 1 is shown in $A$ and $B$ and stent 2 is shown in $C$ and $D$. Note the relatively unchanged transition Zone ${ }_{2}$ compared with the compaction Zone $e_{3}$ that decreases in porosity with stent compaction. The $Y$ construction is shown in $E$, with compaction of stent 2 in $F$, still leaving high-porosity Zone ${ }_{2}$. In vivo images of corresponding stent configurations are shown in $G, H$, and $I$. Neointima formed only on low-porosity zones.

Braided self-expandable stents display various porosities according to deployment technique. What kind of porosities can be achieved with stent compaction, with the intent of further closure of the aneurysm neck? The amount of metallic coverage of the aneurysm neck provided by the 2 stenting techniques that will be used in vivo presumably affects the capacity of stents to support coiling, the neointimal coverage of stent struts and closure of the neck, and the capacity for the stents to modify aneurysm flows, if they have any. Bench studies have been performed to systematically observe the effects of stent compaction on device porosity by using a single stent or a stenting technique. Finally, in vivo, do stents provide a scaffold for neointima formation, as is often claimed? ${ }^{2,6,9}$

\section{MATERIALS AND METHODS \\ Braided Self-Expandable Stents}

Braided self-expandable stents were nitinol single-wire (56 $\mu \mathrm{m}$ in diameter) weave devices, nominal diameter and length $4.5 \times 30$ $\mathrm{mm}, 89 \%$ porosity (in $3.5-\mathrm{mm}$ tubes), 16 struts, $0.6 \pm 0.5$ pores/ $\mathrm{mm}^{2}$ (gifts from MicroVention, Aliso Viejo, California).

\section{Bench Studies}

Bench studies modified from Makoyeva et $\mathrm{al}^{14}$ were performed to assess device deformation when constrained in such a fashion as to mimic deployment in bifurcations and secondary effects when stents are compacted (Fig 1). Scaled photographs were studied with an image-processing program to measure porosity, pore density, and strut frequency when stent extremities were deployed into 2-, 2.5-, and 3-mm silicone tubes, leaving the midstent portion free to expand; stents were compacted by 0 - to $7-\mathrm{mm}$ increments.

\section{In Vivo Studies}

Aneurysm Construction. Protocols for animal experimentation were approved by the institutional Animal Committee in accordance with guidelines of the Canadian Council on Animal Care. All procedures were performed with the animals (24 Beagle dogs) under general anesthesia. Wide-neck venous pouch aneurysms were constructed by using a variant of the Y-type bifurcation model created between the 2 common carotid arteries as described previously. ${ }^{13}$ In brief, through a midline incision, the left external jugular vein was harvested. The left common carotid artery was ligated near its origin and transected. The distal end was mobilized and tunneled to the contralateral side between the esophagus and trachea. A 2-cm venous segment, cleaned from fat and adventitia, was prepared for the anastomosis as depicted in Fig 2. All structures were anastomosed with the use of 7.0 Prolene running sutures (Ethicon, Cincinnati, Ohio). The model was modified to mimic the clinical situation, in which the neck incorporates the origin of a branch. In the resulting model, the "anatomic neck" of the aneurysm, consisting of the wall of the venous segment, is wide and devoid of suture lines, whereas the "surgical neck" forms a dysplastic bifurcation that incorporates the origin of the left carotid artery. Bifurcation aneurysms had 13- to 17-mm sacs and 7- to 9-mm necks (Table).

Endovascular Treatment. Endovascular treatment was performed at least 4 weeks after aneurysm construction, according to techniques routinely used in clinical practice. All animals received $325 \mathrm{mg}$ of aspirin and $75 \mathrm{mg}$ of clopidogrel each day for 4 days 


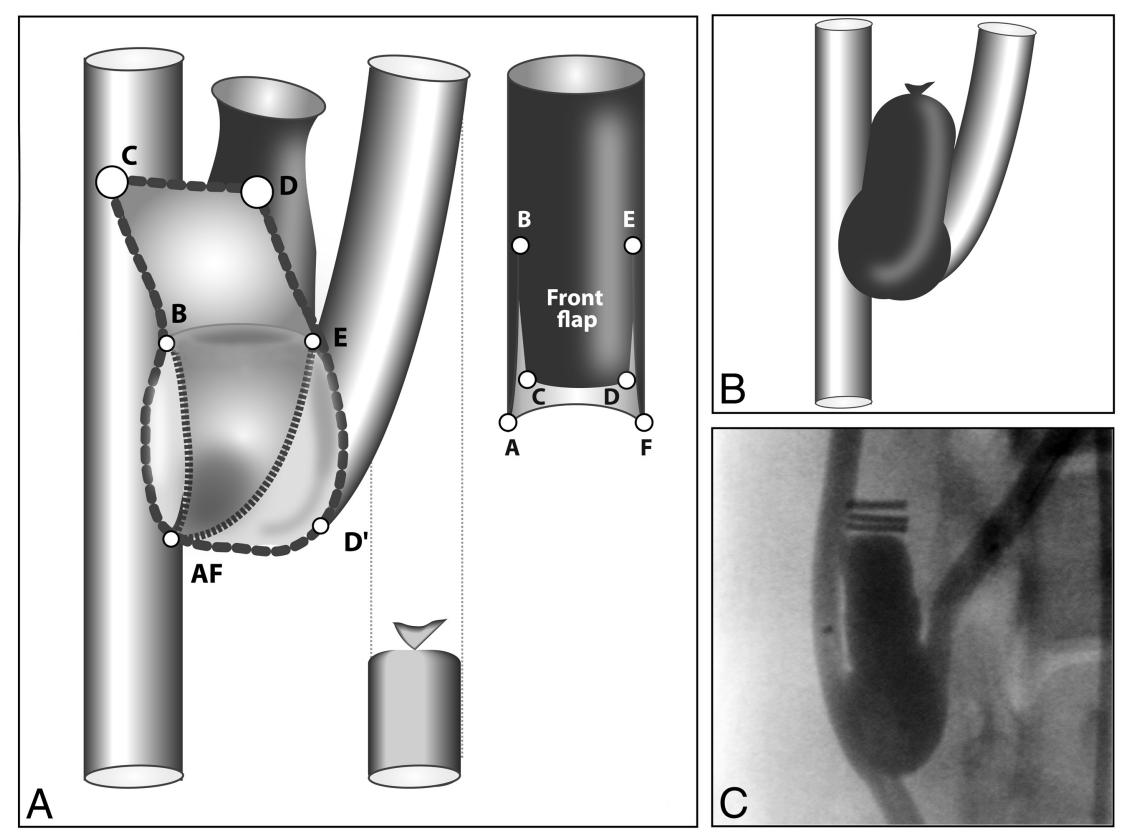

FIG 2. Surgical construction of aneurysms. The dysplastic bifurcation is constructed by creating a front and a back flap $(A)$. Points $A F$ are sutured together at the back, while the front flap is closed by suturing point $C$ to $A F$ and $D$ to $D^{\prime}$, resulting in a wide-neck bifurcation aneurysm $(B)$. An example is shown at angiography in $C$.

before endovascular treatment. Clopidogrel was discontinued 10 days after embolization or stent placement, whereas $325 \mathrm{mg} /$ day aspirin was continued until the dogs were euthanized. A bolus of $300 \mathrm{U}$ of heparin was IV-administered after placement of $5 \mathrm{~F}$ or $6 \mathrm{~F}$ introducer sheaths in one or both femoral arteries. All procedures were performed by using a single plane coronary angiography unit without the capacity for subtraction (HiCor; Siemens, Erlangen, Germany). Multiple angiographic projections were performed to find the appropriate "coiling view," and selective carotid injections were repeated after deployment of each device (stent or coil). Microcatheters (Headway 17 and 21), stents, and platinum coils were provided by MicroVention. To control bias, animals were randomly allocated to 5 different treatment groups (of approximately 5 animals each, a sample size that can detect only large effects), leading to slight imbalance in the number of animals per group: standard coiling $(n=6)$, single stent-assisted coiling $(n=5)$, Y stent-assisted coiling $(n=5)$, Y-stenting only $(n=4)$, and no treatment $(n=4)$. Coil embolization, with or without stenting, was performed by maximal packing with 0.014 caliber platinum coils of decreasing diameters, followed by smaller coils (2-4 $\mathrm{mm}$ in diameter; caliber 0.010$)$, until coils could no longer be introduced without protruding at the level of the bifurcation, or until the microcatheter was ejected from the aneurysm. Stenting was performed through a bifemoral approach; when using 1 stent, one femoral artery was used to catheterize the aneurysm, the other was used to deploy the stent from the distal left carotid artery to the proximal right carotid artery, thereby jailing the microcatheter. To perform Y-stenting, the same procedure was used, but after deployment, the stent was compacted and shortened to protrude horizontally across the neck, followed by deployment of a second stent from the distal to the proximal right carotid artery (Fig $1 E,-F)$. The jailed micro- catheter was then used for coiling. Femoral arteries were ligated to prevent hematoma formation.

\section{Angiographic Outcomes}

Immediate and 3-month follow-up angiograms were independently graded, on a 4-point ordinal scale, by 2 experienced observers (J.R. and I.S.) to assess the degree of aneurysm occlusion. ${ }^{13}$ A score of 0 indicated complete obliteration, 1 indicated a residual neck, 2 indicated a residual or recurrent aneurysm, and 3 indicated a saccular lesion larger than the initial lesion. After assessing intraobserver and interobserver agreement, a consensus session was held to determine final results.

\section{Pathologic Outcomes}

After barbiturate overdose euthanasia at 3 months, carotid aneurysms were removed en bloc and fixed in formalin for 1 week. The right carotid artery was opened distal to and at the level of the bifurcation to visualize the aneurysm neck orifice. The degree of neointimal closure was scored independently by 2 observers according to a scale described previously. ${ }^{13}$ Scores were assigned as follows: 0 , thick neointima completely sealed the orifice of the neck; 1, neointima sealed the neck but with small residual holes; 2 , a crescent was present around the aneurysm wall and the neointima covering the coil mass; 3 , the coil mass itself was only partially covered with neointima; and 4, no neointima, only thrombus (if anything), was covering the coils or stent struts. Interobserver and intraobserver variability was studied. After scoring neointimal closure for each aneurysm, the same observers analyzed photographs of the neck of stented aneurysms (coiled or not) to assess whether neointima formation occurred over coil loops or stent struts. Overall stent porosity at the level of the aneurysm neck was measured as 1 minus area of metallic surfaces divided by overall neck area. Because stents or Y-stent constructions displayed various porosities, the porosity of stent segments covered with neointima, where it occurred, was measured (as well as the porosity of stent segments not covered with neointima) by delineating circular areas of interest, measuring metallic surfaces divided by the total surface of the circular area, with the use of Image J image-processing software (National Institutes of Health, Bethesda, Maryland; http://rsbweb.nih.gov/ij/docs/index. $\mathrm{html}$ ). The mean porosity of neointima-covered stent segments was then compared with the mean porosity of bare stent segments by using the Student $t$ test.

\section{Statistics}

Intraobserver and interobserver agreement on the scored angiographic and pathologic outcomes were measured by using $\kappa$ statistics. ${ }^{14}$ Aneurysm dimensions, packing attenuation, immediate and follow-up angiographic results, and neointimal scores for all treated aneurysms were compared by using nonparametric 


\begin{tabular}{|c|c|c|c|c|c|c|c|c|c|}
\hline \multirow[b]{2}{*}{ Groups } & \multicolumn{4}{|c|}{ Aneurysm Parameters } & \multirow{2}{*}{$\begin{array}{c}\text { Coil } \\
\text { Volume } \\
\left(\mathrm{mm}^{3}\right)\end{array}$} & \multirow{2}{*}{$\begin{array}{c}\text { Packing } \\
\text { Density } \\
(\%)\end{array}$} & \multicolumn{3}{|c|}{ Median Scores } \\
\hline & $\begin{array}{l}\text { Long Axis } \\
\text { (mm) }\end{array}$ & $\begin{array}{l}\text { Short Axis } \\
\text { (mm) }\end{array}$ & $\begin{array}{l}\text { Neck } \\
(\mathrm{mm})\end{array}$ & $\begin{array}{c}\text { Volume } \\
\left(\mathrm{mm}^{3}\right)\end{array}$ & & & Initial & 3 Months & Neointima \\
\hline Coils only $(n=6)$ & $15.2 \pm 1.0$ & $7.3 \pm 0.5$ & $7.5 \pm 0.8$ & $655 \pm 62$ & $170 \pm 49$ & $25.9 \pm 6.2$ & 1 & 2 & 2 \\
\hline 1 stent + coils $(n=5)$ & $17.2 \pm 2.8$ & $8.0 \pm 2.0$ & $8.8 \pm 1.9$ & $991 \pm 603$ & $136 \pm 43$ & $16.9 \pm 7.7$ & $0^{\mathrm{a}}$ & $0^{a}$ & 2 \\
\hline 2 stents + coils $(n=5)$ & $13.6 \pm 3.6$ & $7.0 \pm 0.7$ & $6.6 \pm 1.1$ & $548 \pm 312$ & $115 \pm 30$ & $24.0 \pm 7.7$ & 1 & 1 & 2 \\
\hline 2 stents $(n=4)$ & $16.8 \pm 1.0$ & $6.8 \pm 0.1$ & $8.5 \pm 0.6$ & $699 \pm 140$ & & & 2 & 3 & $4^{\mathrm{b}}$ \\
\hline Controls $(n=4)$ & $16.0 \pm 5.5$ & $10.8 \pm 1.3$ & $8.4 \pm 1.0$ & $1053 \pm 547$ & & & 2 & 3 & \\
\hline
\end{tabular}

Note:-Values are reported as mean \pm SD.

a Stent-assisted coiling led to more complete occlusions initially $(P=.013)$ and at 3 months $(P=.010)$ than coiling alone.

${ }^{\mathrm{b}}$ Aneurysms treated with $Y$-stenting only had significantly worse neointimal results than all other groups $(P=.023)$.

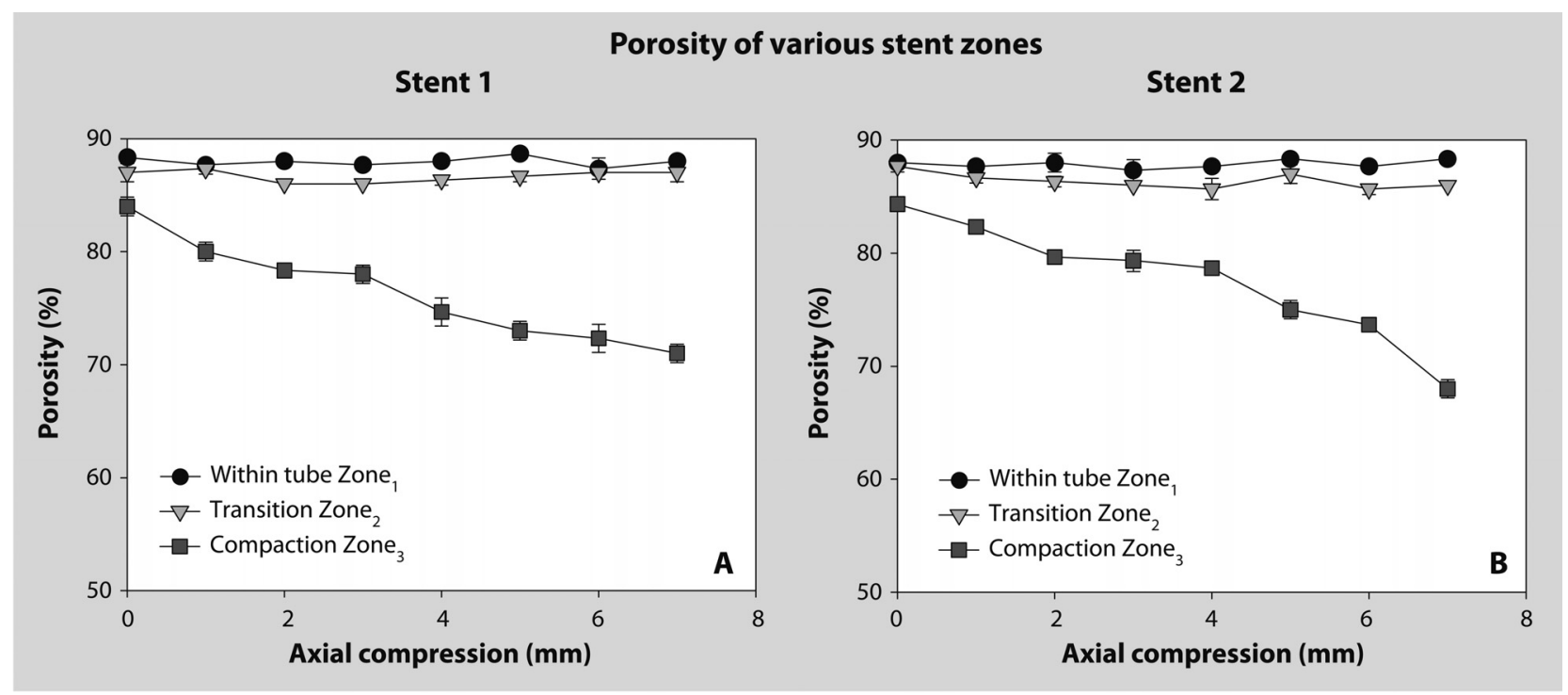

FIG 3. Stent compaction and porosity. In vitro studies showing the effects of stent compaction on different segments or zones of stents when extremities are inserted in 2 -mm tubes. Effects on stent 1 are shown in $A$, on stent 2 in $B$. While the porosity of Zone ${ }_{3}$ can be significantly decreased with stent compaction, the transition Zone ${ }_{2}$ remains relatively unchanged.

Kruskal-Wallis tests, followed by $2 \times 2$ Mann-Whitney tests, when appropriate. Simple coiling was compared with single stentassisted coiling and with Y-stent-assisted coiling, separately, and then combined. A $P$ value $\leq .05$ was considered significant.

\section{RESULTS}

\section{Bench Studies}

The single and Y-bifurcation stenting configuration was reproduced by using bench studies. Stent porosity significantly varied according to 3 different zones (Fig 1). The transition Zone ${ }_{2}$ underwent minimal change with shortening from 0 to $7 \mathrm{~mm}$, but the compaction Zone $_{3}$ significantly decreased in porosity, proportionate to device shortening, reaching $65 \%$ with maximum compaction (Fig 3).

\section{In Vivo Results}

Aneurysm sac and neck dimensions, coil-packing densities, angiographic results, and neointimal scores are summarized in the Table and illustrated in Fig 4. There were no significant differences in aneurysm dimensions, length of coils, volumes of coils, or packing densities $(P=.13)$ between groups treated with simple or stent-assisted coiling.
The $\kappa$ values for interobserver and intraobserver agreement in the evaluation of angiographic results at implantation were substantial $(0.628 \pm 0.156$ and $0.625 \pm 0.135)$ but at 3 months were slight to substantial ${ }^{15}(0.454 \pm 0.149$ and $0.732 \pm 0.117)$. The $\kappa$ values for interobserver and intraobserver agreement in the evaluation of neointima formation at 3 months varied from slight to substantial $(0.412 \pm 0.135$ and $0.671 \pm 0.123)$.

Coiled aneurysms tended to recur at 3 months, with increasing scores for all animals, whereas angiographic results were more often stable (8 of 10) after stent or Y-stent-assisted coiling (Fig 4). Final angiographic results differed significantly between treated groups $(P=.005)$. Y-stenting, without coiling, uniformly failed to treat aneurysms, just like controls ( 0 of 4 of both groups had any evidence of occlusion). Single stent-assisted coiling led to more complete occlusions initially $(P=.013)$ and at 3 months $(P=$ $.010)$ than coiling alone. Y-stent-assisted coiling was not significantly different from simple coiling or from single stent-assisted coiling. Neointimal scores differed significantly between aneurysms treated with $Y$-stenting only and coiled groups $(P=.028)$ but not between coiling and single-stent or Y-stent-assisted coiling $(P=.908)$.

Coils at the neck of treated aneurysms were always covered with neointima at 3 months. In vivo stent porosities varied be- 

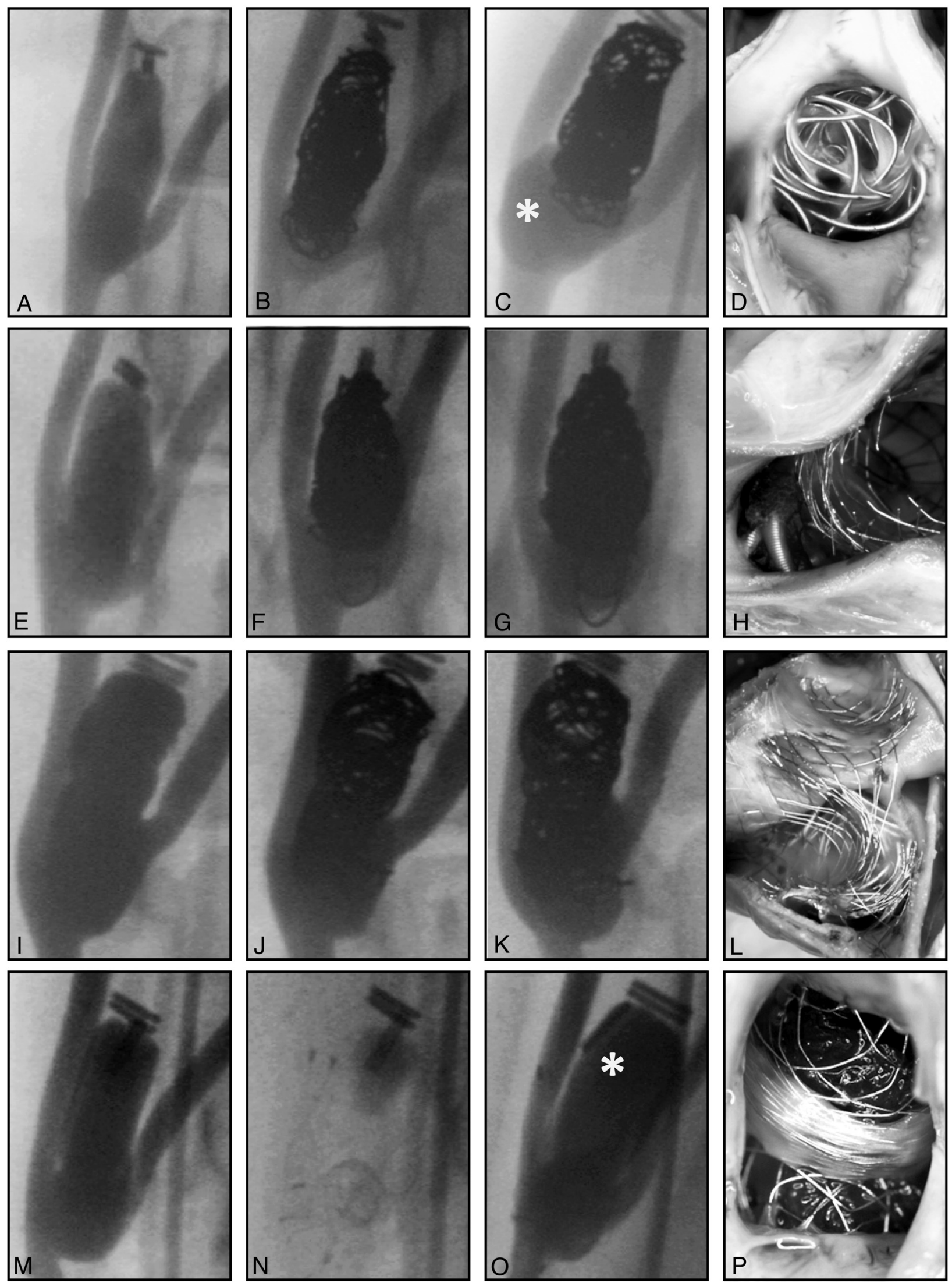

FIG 4. Endovascular treatment groups. Selected frames of angiographic series showing aneurysms before $(A, E, I, M)$, immediately after (B,F,J,N), and 3 months after treatment $(C, G, K, O)$, and photographs of the aneurysm ostium $(D, H, L, P)$ in animals treated by coiling $(A-D)$, single stentassisted coiling $(E-H)$, Y-stent-assisted coiling $(I-L)$, and $Y$-stenting $(M-P)$ showing recurring aneurysm with simple coiling (asterisk in $C$ ), better results with stent-assisted coiling, and the absence of therapeutic effect with $\mathrm{Y}$-stenting only (asterisk in $\mathrm{O}$ ). $N$ was taken at the end of the angiographic series, to show the $Y$ disposition of stents. 

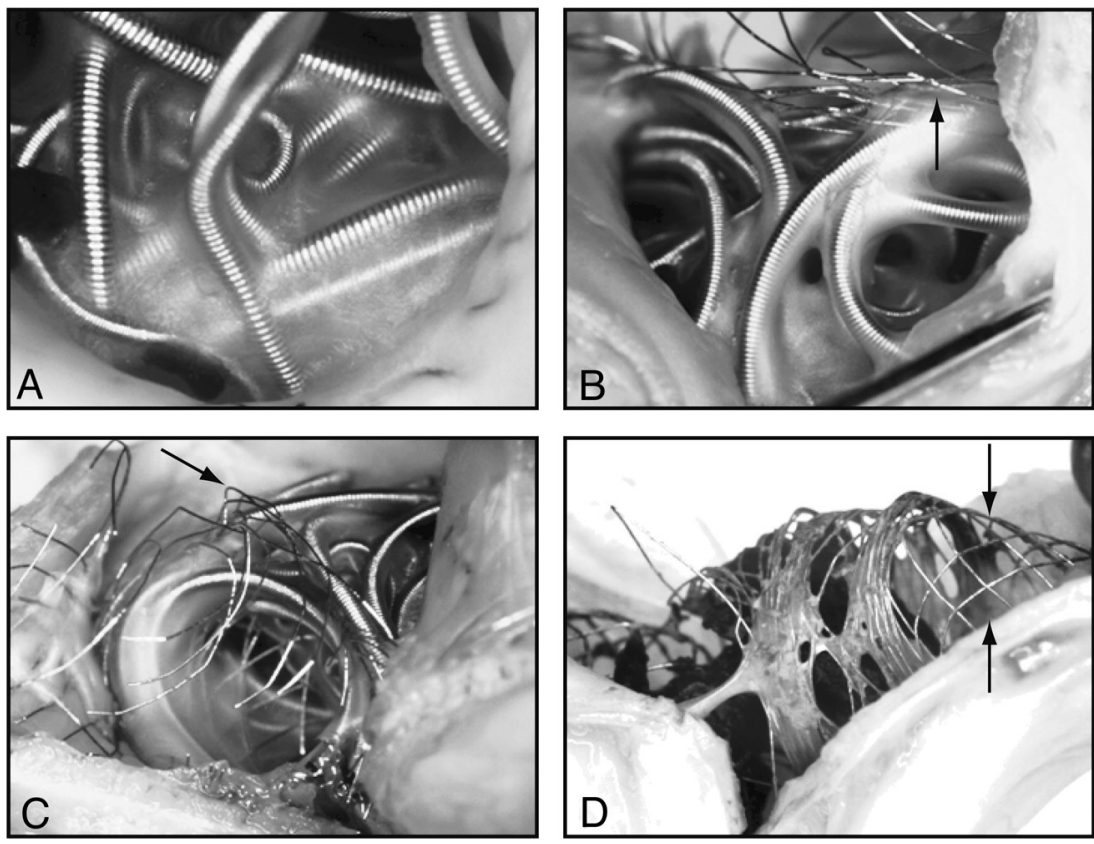

FIG 5. Neointimal closure of aneurysm necks. Photographs of specimens 3 months after coiling $(A)$, single stent-assisted coiling $(B)$, $Y$-stent-assisted coiling $(C)$, and $Y$-stent placement only $(D)$, showing how neointima formed mainly on coil loops. Bare stent struts are shown by arrows in $B$ and $C$. Note widely open pores in transition zone ${ }_{2}$ after $Y$-stent placement only (arrows in D). angiographic results with stent-assisted compared with simple coiling, aneurysms were hardly comparable, and stents were associated with higher complication and mortality rates. ${ }^{7,16}$ Other clinical reports have claimed that stent placement may not prevent the frequent recanalization observed in difficult, wide-neck or bifurcation aneurysms. ${ }^{17}$ A randomized comparison between simple or balloon-assisted coiling and stent-assisted coiling has yet to be performed. ${ }^{8,18}$

Given their widespread clinical use, the paucity of preclinical studies on selfexpandable intracranial stents in the treatment of aneurysms is remarkable. Balloon-expandable stents have been shown to have some efficacy by themselves as early as $1994,{ }^{19-21}$ and the feasibility of stent-assisted coiling of lateral wall porcine aneurysms was already reported in $1993 .^{22-26}$ The potential clinical value of stent placement cannot be inferred from those animal models that have a propensity for anatomic cures, no tween $92 \%$ and $40 \%$. Stent struts were covered with neointima only on stent segments or zones compacted to a porosity of $60 \%$ or less. The mean porosity of neointima-covered stent segments $(49.2 \pm 8.1 \%)$ differed significantly from bare stent segments $(84.9 \pm 7.3 \% ; P=.000)$. Y-stent constructions uniformly showed higher porosities at the transition zones $\left(\right.$ Zone $_{2}$ of bench studies), devoid of neointima formation, leaving large holes for flow to persist (Fig 5).

\section{DISCUSSION}

The main findings of this study are that stent-assisted coiling of bifurcation aneurysms can lead to better angiographic results at 3 months compared with simple coiling, a phenomenon that seems to result from more complete occlusions initially. Stents alone had little or no effect on aneurysm occlusion, and neointima formation was almost completely restricted to portions of stent adjacent to coils. In addition, we found that reconstruction of a bifurcation is possible with the use of braided stents and Y-stenting, and that intentional reduction of stent porosity can be achieved with stent compaction, both in bench studies and in vivo, but a limiting factor was the constant presence of transition Zone $_{2}$, showing higher porosities than other stent segments in all cases. If stents can help support coil embolization of aneurysms and improve initial results, they remain too porous to provide a significant scaffold for neointima formation. When stents are compacted to decrease porosity and, ideally, to increase metallic coverage of the neck and reconstruction of the bifurcation, the strategy may still fail because compaction has no effect on the relatively more porous transition Zone $_{2}$, located at the junction between the neck area and the parent vessel or branch.

Although some case series have reported improved long-term matter what treatment is applied. ${ }^{27-29}$ Stenting of experimental aneurysms has been tested in lateral wall models, in pigs ${ }^{25}$ or in dogs, ${ }^{30,31}$ and, although both successes and failures have been reported, none of the published studies has used braided selfexpandable stents, and none has used bifurcation aneurysm models. The model described here recurred after simple coiling and could reproduce the difficulties involved in stenting bifurcations.

Many authors have claimed that stents could have an effect by themselves or could provide a scaffold on which neointima could form. ${ }^{2,6}$ The present work could not support these claims, and if the use of stents led to improved angiographic results at 3 months, this seems related to better initial aneurysm occlusions permitted by the stent.

If in vivo experiments have shown that neointimal coverage of stent struts depends on their concentration or metallic density (1-porosity), in vitro experiments have revealed that compacting braided stent during deployment can decrease porosities, except at the transition Zone ${ }_{2}$, which consistently remains relatively porous. These porous "windows," located at the junction of the branch and the aneurysm neck in Y-stenting, probably affect the capacity for these stents to retain coil loops during coiling and are void of neointima at 3 months. It would be important for interventionists to predict what kind of metallic closure of aneurysm or what kind of reconstruction of the bifurcation occurs when they use such devices. Nominal porosities typically provided by manufacturers do not suffice to predict the porosities that will be delivered in clinical cases and that are so dependent on anatomy and deployment techniques. Simple bench experiments could serve to construct graphs or tables specific to each device that would help guide appropriate clinical use.

AJNR Am J Neuroradiol 34:570-76 Mar 2013 www.ajnr.org 


\section{Limitations}

The model described here does not mimic the broad-neck aneurysms for which coiling cannot be achieved without assistance. Had this been the case, no comparison would have been possible between stent-assisted coiling and coiling alone. The model cannot be completely occluded with coiling alone, however, without jeopardizing the parent artery or branches. Our results do not apply to sidewall aneurysms. The lack of subtraction in the angiographic assessment of results is a weakness of the study.

We studied only 1 stent, a braided device that differs significantly from laser-cut stents commonly used in many endovascular centers. The device belongs to the same family as the Leo stent (Balt, Montmorency, France) and has recently been introduced in Europe and Canada (LVIS; Microvention), but we do not know if our results apply to other devices. The number of animals studied in this work was small, and follow-up angiography beyond 3 months was not performed. Experimental aneurysms were surgical constructions, and results may differ significantly from spontaneous intracranial aneurysms. Canine biology differs from human biology; extrapolation to human applications should always be prudent.

\section{CONCLUSIONS}

Stent-assisted coiling may improve angiographic results compared with simple coiling, but these high-porosity stents did not provide a scaffold for more complete neointimal closure of aneurysms.

Disclosures: Jean Raymond—RELATED: Grant: Fond de la recherche en santé du Québec, Heart and Stroke Foundation, Comments: Academic, peer-reviewed research funding; money paid to institution. Grants/Grants Pending: MicroVention, Comments: Money paid to institution.

\section{REFERENCES}

1. Higashida RT, Smith W, Gress D, et al. Intravascular stent and endovascular coil placement for a ruptured fusiform aneurysm of the basilar artery. Case report and review of the literature. J Neurosurg 1997;87:944-49

2. Lanzino G, Wakhloo AK, Fessler RD, et al. Efficacy and current limitations of intravascular stents for intracranial internal carotid, vertebral, and basilar artery aneurysms. J Neurosurg 1999;91:538-46

3. Mericle RA, Lanzino G, Wakhloo AK, et al. Stenting and secondary coiling of intracranial internal carotid artery aneurysm: technical case report. Neurosurgery 1998;43:1229-34

4. Huang Q, Xu Y, Hong B, et al. Stent-assisted embolization of wideneck anterior communicating artery aneurysms: review of 21 consecutive cases. AJNR Am J Neuroradiol 2009;30:1502-06

5. Lavine SD, Meyers PM. Application of new techniques and technologies: stenting for cerebral aneurysm. Clin Neurosurg 2007;54: 64-69

6. Lubicz B, Bandeira A, Bruneau M, et al. Stenting is improving and stabilizing anatomical results of coiled intracranial aneurysms. Neuroradiology 2009;51:419-25

7. Piotin M, Blanc R, Spelle L, et al. Stent-assisted coiling of intracranial aneurysms: clinical and angiographic results in 216 consecutive aneurysms. Stroke 2010;41:110-15

8. Raymond J, Darsaut TE. Stenting for intracranial aneurysms: how to paint oneself into the proverbial corner. AJNR Am J Neuroradiol 2011;32:1711-13

9. Shapiro M, Becske T, Sahlein D, et al. Stent-supported aneurysm coiling: a literature survey of treatment and follow-up. AJNR Am J Neuroradiol 2012;33:159-63

10. Chow MM, Woo HH, Masaryk TJ, et al. A novel endovascular treatment of a wide-necked basilar apex aneurysm by using a Y-configuration, double-stent technique. AJNR Am J Neuroradiol 2004;25:509-12

11. Saatci I, Geyik S, Yavuz K, et al. X-configured stent-assisted coiling in the endovascular treatment of complex anterior communicating artery aneurysms: a novel reconstructive technique. AJNR Am J Neuroradiol 2011;32:E113-17

12. Thorell WE, Chow MM, Woo HH, et al. Y-configured dual intracranial stent-assisted coil embolization for the treatment of widenecked basilar tip aneurysms. Neurosurgery 2005;56:1035-40

13. Raymond J, Salazkin I, Georganos S, et al. Endovascular treatment of experimental wide neck aneurysms: comparison of results using coils or cyanoacrylate with the assistance of an aneurysm neck bridge device. AJNR Am J Neuroradiol 2002;23:1710-16

14. Makoyeva A, Bing F, Darsaut TE, et al. The varying porosity of braided self-expanding stents and flow diverters: an experimental study. AJNR Am J Neuroradiol 2012 Aug 9 [Epub ahead of print]

15. Landis JR, Koch GG. The measurement of observer agreement for categorical data. Biometrics 1977;33:159-74

16. Piotin M, Spelle L, Mounayer C, et al. Intracranial aneurysms: treatment with bare platinum coils-aneurysm packing, complex coils, and angiographic recurrence. Radiology 2007;243:500-08

17. Hwang G, Park H, Bang JS, et al. Comparison of 2-year angiographic outcomes of stent- and nonstent-assisted coil embolization in unruptured aneurysms with an unfavorable configuration for coiling. AJNR Am J Neuroradiol 2011;32:1707-10

18. Darsaut TE, Raymond J. The design of the STenting in Aneurysm Treatments (STAT) trial. J Neurointerv Surg 2012;4:178-81

19. Darsaut T, Bouzeghrane F, Salazkin I, et al. The effects of stenting and endothelial denudation on aneurysm and branch occlusion in experimental aneurysm models. J Vasc Surg 2007;45:1228-35

20. Darsaut T, Salazkin I, Ogoudikpe C, et al. Effects of stenting the parent artery on aneurysm filling and gene expression of various potential factors involved in healing of experimental aneurysms. Interv Neuroradiol 2006;12:289-302

21. Geremia G, Haklin M, Brennecke L. Embolization of experimentally created aneurysms with intravascular stent devices. AJNR Am J Neuroradiol 1994;15:1223-31

22. Massoud TF, Turjman F, Ji C, et al. Endovascular treatment of fusiform aneurysms with stents and coils: technical feasibility in a swine model. AJNR Am J Neuroradiol 1995;16:1953-63

23. Szikora I, Guterman LR, Wells KM, et al. Combined use of stents and coils to treat experimental wide-necked carotid aneurysms: preliminary results. AJNR Am J Neuroradiol 1994;15:1091-102

24. Turjman F, Acevedo G, Moll T, et al. Treatment of experimental carotid aneurysms by endoprosthesis implantation: preliminary report. Neurol Res 1993;15:181-84

25. Turjman F, Massoud TF, Ji C, et al. Combined stent implantation and endosaccular coil placement for treatment of experimental wide-necked aneurysms: a feasibility study in swine. AJNR Am J Neuroradiol 1994;15:1087-90

26. Wakhloo AK, Schellhammer F, de Vries J, et al. Self-expanding and balloon-expandable stents in the treatment of carotid aneurysms: an experimental study in a canine model. AJNR Am J Neuroradiol 1994;15:493-502

27. Raymond J, Berthelet F, Desfaits AC, et al. Cyanoacrylate embolization of experimental aneurysms. AJNR Am J Neuroradiol 2002;23: $129-38$

28. Desfaits AC, Raymond J, Muizelaar JP. Growth factors stimulate neointimal cells in vitro and increase the thickness of the neointima formed at the neck of porcine aneurysms treated by embolization. Stroke 2000;31:498-507

29. Bouzeghrane F, Naggara O, Kallmes DF, et al. In vivo experimental intracranial aneurysm models: a systematic review. AJNR Am J Neuroradiol 2010;31:418-23

30 Liu JM, Zhao WY, Zhang Y, et al. Pathology of stented common carotid aneurysm in dogs: comparison between stenting and stent assisted coiling. Interv Neuroradiol 2005;11:333-40

31 Turjman F, Acevedo G, Massoud TF, et al. An experimental study of the treatment of aneurysms using an intravascular prosthesis. J Neuroradiol 1997;24:205-11 